\title{
MAYAN TIME SYSTEMS AND TIME SYMBOLS
}

\section{By CYRUS THOMAS}

That the discovery by $\mathrm{Mr}$ J. T. Goodman ${ }^{1}$ of the signification of certain time and numeral symbols in the Mayan inscriptions, coupled with the discoveries by Dr Förstemann in reference to time counting and also time symbols, must point out and open new channels in the investigation of Mayan hieroglyphics, is evidenit. The determination of characters which had previously received widely different interpretations must cancel a number of previous speculations, and the discoveries must largely influence future attempts toward interpretation of the inscriptions and codices. While Mr Goodman's ungenerous treatment of coworkers in the same field-ignoring entirely the work they had done, though often appropriating it and building thereon-is calculated to give his monograph an unfavorable reception; and although some of his assumed discoveries must be rejected as lacking proof and his leading theory discarded as untenable, the new light he has thrown on the subject by his real discoveries, when added to that from Dr Förstemann's investigations, will penetrate the mysteries of the inscriptions and possibly also of the codices. The writer may be permitted to say that he makes this assertion after careful investigation, during which he has tested, one by one, Goodman's renderings by reference to the originals as given in Maudslay's excellent photographic reproductions and drawings, accepting only those sustained by absolute demonstration.

The discoveries mentioned consist chiefly in ascertaining the fact that the time periods or orders of units, which are indicated in

1 Archaic Maya Inscriptions; Maudslay's Biologia Centrali-Americana, pt. virI. 
the Dresden codex by the relative positions of the numerals, or counters, are indicated in the inscriptions by special symbols. It is well known that among the Mayan tribes the vigesimal system was in vogue, and that to express numbers up to 19 (that is, units of the first or lowest order), they used dots and short lines; but to express units of the higher orders the authors of the codices (at least of the Dresden codex) had recourse to relative position. For example, to indicate 5 units of the first order, 4 of the second, I I of the third, and 6 of the fourth, they placed them one above another, thus:

$$
\begin{aligned}
& \text { Fourth order } 6=28,800 \\
& \text { Third order II }=3,960 \\
& \text { Second order } 4=80 \\
& \text { First order } 5=5 \\
& 32,845
\end{aligned}
$$

- twenty of the first order making one of the second, I 8 of the second one of the third, 20 of the third one of the fourth, and so on; the number of the second order to make one of the third having been changed in time counting from the regular vigesimal order to I8, apparently to conform to the number of months in a year and thus to facilitate counting. It is apparent, therefore, that the value of one unit of each of the different orders in time counts was as follows, the day being the primary unit:

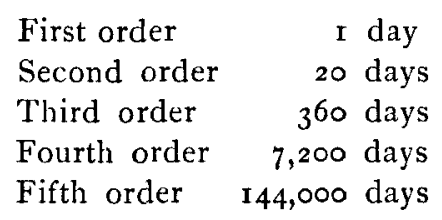

Now, Mr Goodman has discovered that in the inscriptions the orders of units (or real time periods as he believes them to be) were indicated not by relative position, but by specific characters. To these orders of units (or time periods, as he terms them) he 
has applied (except the first) arbitrary names, as follows: To the first or lowest, day or kin; to the second, chuen; to the third, ahau; to the fourth, katun; to the fifth, cycle; and to the sixth, great cycle; each having its symbol.'

Mr Goodman has further discovered that in the inscriptions a date is frequently followed by a number series and this by another date, and that, as in the codices, this intervening number indicates exactly the lapse of time from one of the given dates to the other. As this, when several times repeated with different dates and different numbers, amounts to actual demonstration, we are compelled to accept his claimed discoveries as real, so far as thus proven. As I have presented in detail, in a paper now in course of preparation, the data verifying these discoveries so far as the data afford demonstration, a simple statement of the fact must suffice here.

Although credit is due chiefly to Dr Förstemann for demonstrating the method of expressing high numbers in the Dresden codex, which has been followed with further evidence by the writer, I may note in passing that we seem to have overlooked the fact of the near approach of this method to that of the

\footnotetext{
'Although we speak of this discovery as Mr Goodman's, yet we would do $\mathrm{Dr}$ Forstemann injustice if we should overlook the fact that part of the credit is due to him. Not only had he discovered and applied to the time series in the Dresden codex the orders of units accepted and used by Mr Goodman, but in fact had determined as early as $189 \mathrm{I}$ the value of the symbols designated ahau and katun by $\mathrm{Mr}$ Goodman, as appears from his article "Zur Maya-Chronologie" in the Zeitschrift für Ethnologie for that year. Mr Goodman's paper was not published until 1897, although it appears from his preface that it was completed in I 895. If Dr Förstemann had not seen Mr Goodman's paper when his article titled "Die Kreuzinschrift von Palenque," was published in Globus in 1897 , and it makes no reference to the former, it is evident that he had discovered independently the value of the symbols which Mr Goodman designates chuen and cycle. It is evident also from the figures (numbers) be gives in his "Zur Enlzifferung der Mayahandschriften," IV. (I894), that Dr Förstemann had discovered as early as June, I 89.4 , the value of most if not all the five time-period symbols, as these figures are based on the series found on the stela and altars at Copan, as given by Maudslay. To the 360 -day period Förstemann applied the name "old year," and to the 7200-day period the name "old ahau" ; but he failed to discover their use. The chief credit therefore for this important discovery should be given to Mr Goodman.
} 
ordinary decimal system of the present day, which has been suggested - though not expressly dwelt on therein - by reading Professor McGee's able paper on The Beginning of Mathematics ${ }^{2}$; in the one, as in the old Babylonian notation, it is by steps up. ward, in the other by steps to the left.

One important result of Mr Goodman's discovery is the evidence it furnishes of the strong similarity, if not absolute identity, of the time systems or calendars of the different Mayan tribes. To call attention to this point is the chief object of this paper. By means of his discovery we are enabled to determine positively the dates where the symbol is obscure or doubtful, and the numeral or time-period symbols where they vary from the typical forms. It was in this way that the advance in the interpretation of the time and numeral symbols of the Dresden codex was made and the explanation of their use and office was given.

The names and order of the days of the month given for the Maya (i. e., the Maya proper, or Yucatecs) and the Tzental and Quiche-Cakchiquel tribes, as based on historical evidence, are as follows :

\begin{tabular}{llllll}
\multicolumn{1}{c}{ Maya } & Tzental & $\begin{array}{c}\text { Quiche- } \\
\text { Cakchiquel }\end{array}$ & \multicolumn{1}{c}{ Maya } & Tzental $\begin{array}{c}\text { Quiche- } \\
\text { Cakchiquel }\end{array}$ \\
r. Imix & Imox & Imox & I I. Chuen & Batz & Batz \\
2. Ik & Igh & $I k$ & r. Eb & Euob & Ee \\
3. Akbal & Votan & Akbal & I3. Ben & Been & Ah \\
4. Kan & Ghanan & Kat & 14. Ix & Hix & Balam \\
5. Chicchan & Abagh & Can & 15. Men & Tziquin Tziquin \\
6. Cimi & Tox & Camey & I6. Cib & Chabin Ahmak \\
7. Manik & Moxic & Queh & 17. Caban & Chic & Noh \\
8. Lamat & Lambat & Canel & 18. Ezanab & Chinax & Tihax \\
9. Muluc & Molo & Toh & 19. Cauac & Cahogh Cooc \\
10. Oc & Elab & 'lzi & 20. Ahau & Aghaual Hunahpu
\end{tabular}

The names in italics are the supposed dominical days in the calendars of the different tribes. That the dominical days of the Troano codex, which is generally attributed to the Maya of

1 American Anthropologist (N. S.)., vol. I, October, 1899. 
Yucatan, were Kan, Muluc, Ix, and Cauac, is conceded; and that those of the Dresden codex, which are known to correspond with those of the inscriptions at Palenque, were Akbal, Lamat, Ben, and Ezanab, is also admitted. Goodman, it is true, shifts the initial day, but his method of counting gives the same result. It is seen, however, by reference to the list, that the three calen. dars, according to the historical evidence, begin the years with different days, it being assumed that the names opposite one another in the lists are equivalents so far as relative position in the series is concerned. Although the parallel names (names occupying the same relative position) differ considerably from the standpoint of morphology, some are but equivalents (as to signification) in the different tribal dialects; but this does not apply to all, as is evident from the efforts of Drs Brinton and Seler to bring them into harmony.' Imix and Imox, Ik and Igh, Kan and Ghanan, Cimi and Camey, Lamat and Lambat, Muluc and Molo, $I x$ and Hix ; Eb, Euob, and Ee; Cauac, Cahogh, and Cooc; and Ahau and Aghaual, are merely different forms of the same names. But this cannot be said of Votan and Akbal, Kan and Kat, nor of most of the other corresponding names.

Turning now to the codices and inscriptions, let us compare the days as represented symbolically in the different sections where found. Of course we cannot say positively to what tribes or to the ancestors of what tribes the inscriptions in the ruins of the different sections are respectively to be attributed. All we can assert positively is that they are Mayan; that those of Palenque are in what is or was the country of the Tzental and Zotzil; those at Menche (or Lorillard city) in the country of the Lacandon; those at Copan and Quirigua in the country of the Quiche and Cakchiquel; and those at Tikal in the country formerly occupied by the Itzae. Nor can we say that uniformity in the form of the day symbols proves positive identity in the names, allowing

\footnotetext{
${ }^{1}$ See also the writer's paper Day Symbols of the Maya Year in the Sixteenth Ann. Rep. Bur. Am. Ethnology (1897).
} 
[N. S., 2, I900

for the variation necessary to express the same idea in the different tribal dialects; nevertheless it tends in this direction, and undoubtedly indicates unity of origin.

That there are in the inscriptions forms of some of the day and month symbols and peculiarities in other characters not observed in the codices is true. But considering what has been stated by early writers as to the names and order of the days and months among the different tribes, the agreement in the forms of the symbols and in the order of the days and months in the inscriptions is remarkable. Take, for example, the day Ahau; although we meet here and there with a face form, the usual symbol at Palenque, Tikal, Menche, and Copan is the same as that found in all the codices. The same is true of the symbols for the days Ik, Akbal, Kan, Ben, Ezanab, Lamat, Chuen, and one or two others. Cimi and Caban vary slightly from the typical form; $M u l u c, E b, M e n$, and $I x$ are of rare occurrence in the inscriptions. Another fact which has an important bearing in the comparison of systems is that each holds its relative position throughout the series in precisely the same order as in the Dresden codex. There is no known variation from this rule. Not only so, but the proof is clear that the years are counted from the same dominical days. For example, we find Ahau occurring on the $3^{\text {d, }} 8$ th, I 3 th, and I 8 th of the month; Akbal on the Ist, 6 th, I Ith, and I6th, which can be true only when Akbal, Lamat, Ben, and Ezanab are the dominical days or year-bearers.

Concerning the question as to how far the similarity in the form of the day symbols can be taken as an indication of a similarity in the names, the following facts are noted: The day Votan in the Tzental calendar stands in the place of $A k b a l$ in the other calendars. Now, akbal, in both Maya and Cakchiquel, signifies "darkness," "night," and " to grow dark," or "become night"; while Votan is the name of a hero-god formerly much venerated by the Tzentals. Votan or uotan is supposed to signify "heart" in the Tzental dialect, and according to Nufiez de la 
Vega he was called "The Heart of the Nation." Yet the symbol of this day is remarkably uniform in the Dresden codex and in all the inscriptions where it appears. The same is true of Kan, Lamat, and Ezanab, which never appear as face characters. As it is admitted that Votan is not equivalent to $A k b a l$, its corresponding name, Kat to Kan, nor Canel to Lamat, how are we to account for the uniformity in the symbols of these days in the several regions which the tribes mentioned are known to have inhabited?

However, the widest variation between the historical evidence and that of the inscriptions is in reference to the names of the months. In regard to these, as given historically, it may be stated that those of the Maya (proper) and the Tzental-Zotzil and Quiche-Cakchiquel groups differed throughout morphologically and in signification, so far as the latter has been determined, no name in one, with a single exception, being the same as that in another. As compared with those in the Maya calendar, which are -
I. Pop
7. Yaxkin
I3. Mac
2. Uo
8. $\mathrm{Mol}$
14. Kankin
3. Zip
9. Chen
15. Moan
4. Zotz
10. Yax
16. Pax
5. Tzec
I1. Zac
I7. Kayab
6. $\mathrm{Xul}$
12. Ceh
18. Cumbu

those of the Tzental were I Tzum, 2 Batzal, 3 Si sac, etc.; those of the Quiche, I Tequexepual, 2 Tziba pop, 3 Zac, 4 Ch'ab, etc., differing in like manner throughout. So widely different, in fact, are they, that Drs Brinton and Seler made no attempt to bring them into harmony. In fact Dr Brinton says: "While the names of the twenty days of each month are practically identical in all the five languages [including Zapotec and Nahuatl] under consideration, the reverse is the case in the names of the eighteen months which made up the vague solar year. These differ widely 
in tribes very closely related, as the Quiches and Cakchiquels; and even in the same dialectic area, as among the Nahuas."

Now, in contrast with this the symbols are not only comparatively uniform in the inscriptions, as shown by the figures given in Mr Goodman's work and in Maudslay's photographs, but with very few exceptions they correspond with those in the Dresden codex. There are also indications that the names were the same as found in the Maya calendar. For example, the symbol of the month Pop is characterized by an interlacing figure apparently intended to denote matting; in Maya pop signifies "mat." The name of the 4th month, Zotz, signifies "a bat," and the symbol, which is always a face form, has an extension upward from the tip of the nose presumably to indicate the leaf-nose bat. But as conclusive evidence on this point, if $\mathrm{Mr}$ Goodman is correct in his interpretation, the month is designated on one of the stelre at Copan by the full form of a leaf-nose bat. So general is the uniformity of the month glyphs, in both the Dresden codex and the inscriptions, that $\mathrm{Mr}$ Goodman has not hesitated to apply the names as given in the Maya calendar, and to place side by side those of the inscriptions with those of the codex. "There is not," he says, "an instance of diversity in all their calendars; their dates are all correlative, and in most of the records parallel each other." Of course there are sporadic variations and imperfect glyphs which often render determination by simple inspection uncertain, but this is generally aided by the connecting numeral series.

The change of day symbols from the typical form to face characters is found in the codices as well as in the inscriptions, as is shown by an examination of the Troano codex, where this is of frequent occurrence. The occasional variations of the symbols for the days Chicchan, Cimi, and $I x$, in the latter codex, are so radical that identity is ascertained only by means of the positions they occupy in series. It is chiefly on this uniformity that $\mathrm{Mr}$ Goodman bases his theory of an archaic calendar.

Another item in the evidence is found in the identity in form 
of the time-period symbols or symbols denoting the orders of units. Though face forms are frequently introduced, the typical forms are the same in the inscriptions of each section, and the face characters are used in each. In addition to the localities mentioned, one or two of the former are found in the inscription on a tablet from Tonina, Chiapas; on an amulet from Ococingo, Chiapas; and on a vase from a Quiche tomb, Guatemala; and at least three of the typical forms are found in the Dresden codex.

We therefore have as evidence on this point the similarity in form of the day, month, and numeral symbols; the uniformity in the order in which the days and months follow one another; the use throughout (except by the Maya of Yucatan) of the same days as dominicals or year-bearers; and in fact, throughout, precisely the same time system and the same method of representing graphically its several features. In addition we find represented in the inscriptions of each locality what Maudslay has appropriately termed "initial series," beginning with a large or quadruple glyph, as that with which the inscription on the Tablet of the Cross at Palenque begins (in the upper left-hand corner of the left slab), and also the same order in placing the glyphs with reference one to another; that is, all are to be read in the same direction. These facts, therefore, indicate much closer uniformity in the time systems of the different sections than that inferred from the historical evidence.

What is the deduction to be drawn from the above-mentioned facts? Is Goodman right when he says: "From this is deducible the important fact that -- whether a single empire, a federation, or separate nations - they were a homogeneous people, constituting the grandest native civilization in the Western Hemisphere of which there is any record"? In other words, do they not show that when the inscriptions were chiseled the Mayan group was much more homogeneous and the tribal distinctions far less marked than when the Spaniards arrived on the scene? $\mathrm{Dr}$ 
Brinton " says that "in all the Mayan dialects the names [of the days] belonged already at the time of the Conquest to an archaic form of speech, indicating that they were derived from some common ancient stock, not one from the other, and that, with one or two possible exceptions, they belong to the stock and are not borrowed words." The inscriptions seem to go far toward confirming this view, which was based wholly on linguistic evidence, although the opinion would imply either that the Maya of Yucatan are to be regarded as the older division of the Mayan group (excepting the Huasteca), or that they had retained, with less change than other tribes, the original names of the days and months.

If the view herein reached be accepted as well founded, the inscriptions and codices will form in this respect a fixed basis for further research into the history of the Mayan tribes. The next step will be to determine from these records, if possible, the probable age of the inscriptions, for, as appears from what has been shown, the history as derived from the early Spanish writers cannot be fully relied on; and the traditions can only be trusted so far as they agree with the monuments and the linguistic evidence. That Mr Goodman's conclusion in this respect cannot be accepted is evident from the quotation given in a previous communication to this journal. ${ }^{2}$

As will be seen, I have limited this paper to a very brief summary of what may be called one branch of the mathematical evidence. To exhaust it would require a comparison of the number and calendar systems of the Mexican codices. Nor have I broached the mystical use of time periods and numerals by the Maya and Nahua, both of which must have an important bearing on the subject treated.

\footnotetext{
1 Native Calendar, p. 2 I.

${ }^{2}$ American Anthropologist, N. s., vol. I, p. 559.
} 